\title{
COMPETÊNCIA SIMBÓLICA E POESIA AFRO-ALEMÃ: REFLEXÕES PARA UMA PERSPECTIVA TRANSLÍNGUE NA FORMAÇÃO DE PROFESSORES DE ALEMÃO ${ }^{1}$
}

\author{
Symbolic Competence and Afro-German Poetry: Reflections for a \\ translanguaging perspective in German Teacher Education
}

\author{
Alessandra de FREITAS \\ Mestre em Letras pela Universidade Federal do Paraná \\ freitasr.alessandra@gmail.com \\ https://orcid.org/0000-0001-6130-1745
}

\begin{abstract}
RESUMO: O presente artigo tem por objetivo articular a noção de competência simbólica como uma possibilidade de prática translíngue nos cursos de graduação de Letras-Alemão com base na utilização de poemas afro-alemães. Para tanto, o conceito de Translinguagem (GARCÍA; WEI, 2014; WEI, 2017) é apresentado, os principais aspectos da noção de competência simbólica (KRAMSCH, 2006; 2009a; 2011a; 2011b; KRAMSCH; WHITESIDE, 2008) são abordados e é oferecido um breve panorama do surgimento da literatura afro-alemã. A partir disso, o poema "die zeitdanach" (o tempo por vir) da pedagoga, ativista e poeta afro-alemã May Ayim é analisado como exemplo e então sua utilização para o contexto de formação de professores é discutida. A partir da análise busca-se demonstrar como poema oferece subsídios para se trabalhar a competência simbólica e pode servir como ponto de partida para sensibilizar os estudantes para o desenvolvimento de uma consciência linguística, histórica, social e política.
\end{abstract}

PALAVRAS-CHAVE: Alemão como Língua Estrangeira; Competência Simbólica; Translinguagem; Poesia Afro-Alemã.

\begin{abstract}
This paper aims at articulating the notion of symbolic competence as a possibility of translanguaging practice in undergraduate German courses in Brazil based on the use of Afro-German poems. Therefore, the concept of Translanguaging (GARCÍA; WEI, 2014; WEI, 2017 ) is presented, the main aspects of the notion of symbolic competence (KRAMSCH, 2006; 2009a; 2011a; 2011b; KRAMSCH; WHITESIDE, 2008) are addressed and a brief overview of the emergence of Afro-German literature is offered. As an example for that, the poem "die zeitdanach" (the time after) by the teacher, activist and
\end{abstract}

\footnotetext{
${ }^{1}$ Este trabalho deriva da dissertação intitulada "Symbolische Kompetenz durch afrodeutsche Lyrik: eine Auseinandersetzung mit dem Thema Rassismusfür die DaF-Lehrerausbildung in Brasilien”, defendida em 26 de fevereiro de 2020, na Universidade Federal do Paraná, sob orientação da Prof. ${ }^{a}$ Dr. ${ }^{a}$ Ruth Bohunovsky.
} 
Afro-German poet May Ayim is analyzed and then its use for the context of teacher education is discussed. From the analysis, the aim is to demonstrate that the poem offers subsidies to work on symbolic competence and can be used as a starting point to sensitize students to the development of linguistic, historical, social and political awareness.

KEYWORDS: German as Foreign Language; Symbolic Competence; Translanguaging; Afro-German poetry.

\section{INTRODUÇÃO}

A existência de estados-nação com suas línguas e culturas nacionais, as línguas padronizadas com gramáticas estáveis, a superioridade das línguas nacionais em relação de dialetos regionais e outras variedades linguísticas e os limites explícitos entre línguas maternas e línguas estrangeiras são algumas das características da modernidade que ainda persistem no campo do ensino de línguas estrangeiras (KRAMSCH, 2014, p. 297). Já há algum tempo, no entanto, esses componentes têm sido questionados e outros modelos têm sido propostos, o que faz com que o ensino de línguas estrangeiras, de acordo com Claire Kramsch (ibid), se caracterize como um fenômeno da modernidade tardia.

No âmbito das reflexões que buscam romper com estes paradigmas na área de Estudos da Linguagem, surge a perspectiva da translinguagem. De acordo com García e Wei (2014), esta perspectiva parte do conceito de languaging, em que este se apresenta como uma alternativa à noção de linguagem como um sistema de estruturas independente; languaging refere-se à ideia de "fazer linguagem", isto é, "ao processo simultâneo de contínuo devir de nós mesmos e de nossas práticas linguísticas, à medida que interagimos e produzimos sentido no mundo",2 (p. 8). Através da combinação com o prefixo trans-, busca-se ressaltar a dinamicidade, heterogeneidade e complexidade das práticas dos usuários plurilíngues ${ }^{3} \mathrm{e}$, sobretudo, apontar que indivíduos plurilíngues não pensam unilateralmente em uma entidade linguística, bem como indicar que o pensamento pressupõe recursos cognitivos, semióticos e modais, que vão além da noção convencional de linguagem em termos de fala e escrita (WEI, 2017, p. 18). A noção de translinguagem, segundo Wei (2017), deve estar associada com uma teoria prática da língua que a enxerga

\footnotetext{
${ }^{2}$ Todas as traduções de trechos do inglês ou do alemão para o português, quando não indicados os tradutores, são minhas. Os excertos originais não foram incluídos devido a limitações de espaço.
} 
como um recurso multilíngue, multissemiótico, multissensorial e multimodal usado para a produção de sentido e significado (p. 22). Com base nesta perspectiva, são reconsideradas as concepções convencionais que traçam uma divisão entre línguas, linguagem, pensamento e identidades socioculturais. Nesse sentido, embora não negue a existência das línguas em si, a perspectiva da translinguagem compreende que línguas são entidades definidas histórica, política e ideologicamente (WEI, 2017, p. 27). Desta forma, segundo o autor, o sujeito plurilíngue seria alguém consciente da existência das entidades políticas das línguas e capaz de usar as características estruturais das línguas que aprendeu. Neste ponto, entendemos que o sujeito precisa adquirir essa consciência em algum momento e,assim, sugerimos que se ocupar da competência simbólica (CS) pode ser uma possibilidade de desenvolver uma consciência que vá além dos supostos limites entre língua(s), subjetividade(s) e contexto(s).

Claire Kramsch desenvolve a noção de CS também no bojo das discussões sobre a necessidade de uma competência translingual e transcultural estar no centro do ensino de línguas estrangeiras atual, uma competência que permita aos estudantes operar entre as línguas (KRAMSCH, 2011b, p. 39). Desta forma, a noção de CS concebida por Kramsch reconhece que aprender uma língua estrangeira não tem somente a ver com a aquisição de estruturas gramaticais e vocabulário da línguas alvo, para comunicar-se em tal língua, mas que isso está associado a um processo de desenvolvimento de uma consciência (meta)linguística, histórica, social e política. É uma perspectiva que compreende, de um lado, a língua nas suas dimensões simbólicas de representação, ação e poder e, de outro, os aprendizes enquanto sujeitos dotados de corpo, mente, emoções e memórias afetivas que não estão separadas do processo de aquisição da língua e caracterizam-se como sujeitos plurilíngues. Além disso, a CS requer uma abordagem ecológica (KRAMSCH; WHITESIDE, 2008), isto é, o entendimento do aprendizado de um idioma nas suas relações estreitas com as subjetividades dos aprendizes, bem como com os contextos históricos, sociais e políticos, nos quais o aprendizado ocorre. Do mesmo modo, ela apresenta uma abertura à aprendizagem estética e, nesse sentido, a literatura assume um papel central para a promoção desta competência.

Neste trabalho nos ocuparemos da poesia afro-alemã, uma literatura que surge na

${ }^{3}$ No presente artigo, opto por utilizar a noção de plurilinguismo quando me refiro a sujeitos/indivíduos e
multilinguismo quando a referência for os contextos e configurações sociais. Nos trechos reproduzidos de

Revista X, v.15, n.1, p. 181-201, 2020. 
década de 1980 na Alemanha com o propósito de tornar visíveis as vozes da diáspora Negra $^{4}$ dentro de uma sociedade que por muito tempo foi imaginada como branca (KILOMBA, 2006). Mais adiante a poesia afro-alemã será melhor descrita, queremos primeiro apontar que o presente artigo pretende abordar a noção de CS no ensino de Alemão como Língua Estrangeira (ALE) através da poesia afro-alemã a partir do enfoque da translinguagem. Interessa-nos refletir sobre o desenvolvimento da CS como uma possibilidade de prática translíngue na primeira etapa da formação de professores de ALE, isto é, nos cursos superiores de licenciatura em Letras-Alemão, e, aliado a isso, discutir o potencial da poesia afro-alemã nas aulas de ALE de contribuir para que os estudantes desenvolvam essa competência.

Consideramos que essas discussões se direcionam, principalmente, para a formação inicial de professores de ALE em contexto brasileiro, pois, conforme aponta Uphoff (2015 apud ARANTES, 2019, p. 25-26) sobre o projeto pedagógico do Curso de Letras Alemão da Universidade de São Paulo, o curso de letras diferencia-se de um curso geral de línguas por conta do seu enfoque metalinguístico, isso significa que, embora muitos dos estudantes aprendem a língua durante a graduação, eles são formados para trabalhar com a língua, e isso requer uma reflexão metalinguística.

Assim, abordaremos a seguir os principais aspectos da concepção de CS e uma aproximação com a perspectiva translíngue, depois apresentaremos de maneira breve a poesia afro-alemã. Posteriormente, a partir da análise de um poema da autora afro-alemã May Ayim, discutiremos seu potencial para ser utilizado nas aulas de ALE com vistas a desenvolver a CS.

\section{COMPETÊNCIA SIMBÓLICA E A PERPECTIVA TRANSLÍNGUE}

O conceito de CS aparece pela primeira vez em um artigo de Kramsch de 2006. Neste texto, Kramsch critica o ensino de línguas estrangeiras que se baseia num entendimento funcional e utilitarista da língua bem como na competência comunicativa

\footnotetext{
outros autores, irei manter a expressão utilizada pelo autor em questão.

${ }^{4}$ Aqui gostaria de ressaltar que estou escrevendo sobre a produção literária de mulheres negras, mas sou uma pesquisadora latino-americana branca, por isso me oriento por conceitos e termos que essas autoras negras mesmas usa(ra)m. Dessa forma, ao longo do texto, a palavra Negra/Negro será grafada em letra maiúscula pois refere-se, neste estudo, não ao atributo biológico cor da pele, senão a uma realidade e identidade política.
} 
como o objetivo final do aprendizado. A crítica consiste em que, por um lado, a abordagem comunicativa (Communicative Language Teaching) pressupõe a inclusão de falantes não-nativos na comunidade dos falantes nativos da língua-alvo, e por outro lado, que ele objetiva uma comunicação precisa e eficiente, que resolva problemas e apresente resultados, o que exclui aspectos como afetividades e subjetividades. Kramsch vê essa divisão dicotômica entre falantes nativos e não-nativos como obsoleta, uma vez que ela considera que atualmente os sujeitos são plurilíngues e nem sempre aprendizes de uma língua relacionam-se (ou devam relacionar-se somente) com falantes nativos da línguaalvo. De acordo com Kramsch, sujeitos plurilíngues são

pessoas que usam mais do que uma língua diariamente, aprendendo uma língua estrangeira ou segunda língua na escola, ou falando duas ou mais línguas em operações diárias, ou escrevendo e publicando em uma língua que não é aquela com a qual elas cresceram. Na maioria dos casos, elas tiveram que aprender uma ou mais línguas enquanto crianças e aprenderam as outras em várias configurações, formais ou informais. Elas podem não falar essas línguas igualmente bem, nem ser igualmente fluentes em todas as circunstâncias e há aquelas que sabiam uma língua, mas a esqueceram em alguma medida. Eu também incluo as muitas pessoas que são capazes de entender uma língua familiar, mas não a falam realmente, aquelas que foram proibidas de falar a língua de casa e cuja única língua agora é a da escola, e aquelas que costumavam falar uma língua, mas que, por conta de experiências dolorosas do passado, hoje recusam a fazê-lo. Esses falantes silenciados podem ser, em algum grau, sujeitos multilíngues (KRAMSCH, 2009a, p. 17).

A partir desta definição é importante ressaltar que não é determinante o nível de proficiência que o falante tem em uma língua, mas as relações subjetivas que ele estabelece com tal idioma. Dessa forma, aqui já aparece um dos importantes pressupostos da CS: o pluri/multilinguismo. Kramsch critica a visão monolíngue do ensino de línguas estrangeiras e reflete sobre sujeitos plurilíngues e contextos multilíngues principalmente a partir do marco da globalização. Para a autora, estes sujeitos dispõem de um entendimento múltiplo incorporado da realidade social, uma sensibilidade plurilíngue que os permite compreender de maneira ampla e complexa as pessoas e os eventos.

As dimensões histórica, social e política da língua e do contexto no qual o aprendizado acontece são também levadas em conta no desenvolvimento da CS. Daí o outro pressuposto desta competência, a saber a abordagem ecológica. Pensar no ensino de língua estrangeira desde uma perspectiva ecológica requer compreender que a aquisição 
de um idioma está localizada em um tempo e espaço definidos, mas que carregam uma densa historicidade, que ela é uma atividade mediada semiótica e socialmente bem como orientada discursivamente e além disso é atravessada pelas subjetividades de todos os seus atores.

Atrelado a isso, Kramsch e Whiteside identificam que os falantes transitam por contextos multilíngues e têm que lidar com situações cotidianas em que os interlocutores usam diferentes línguas, dialetos e registros com diferentes propósitos. Nesse sentido, eles precisam mediar encontros complexos entre interlocutores com capacidades diferentes de linguagem e imaginação cultural, que possuem memórias sociais e políticas distintas e não compartilham necessariamente um entendimento comum da realidade social em que vivem (KRAMSCH; WHITESIDE, 2008, p. 646). Mais do que uma competência baseada na eficiência de comunicar sentidos, os estudantes de línguas estrangeiras precisam hoje de uma competência que os ajude a compreender a prática da construção de sentidos (KRAMSCH, 2006, p. 251).

Em alguns de seus textos, Kramsch retoma o relatório da Modern Language Association, publicado em 2007, que sugere uma reorientação do ensino de línguas estrangeiras, sobretudo para jovens adultos. De acordo com a autora, o relatório aponta que a aquisição de uma competência translingual e transcultural deveria estar no centro do ensino de línguas estrangeiras, uma competência que permitisse aos estudantes operar entre as línguas (KRAMSCH, 2011b, p. 39). Nessa direção, Kramsch aproxima a concepção da CS de uma perspectiva translíngue na medida em que rejeita uma visão monolíngue dos sujeitos e da aquisição/do aprendizado de uma língua e se volta para o desenvolvimento de uma consciência "entre-línguas" (zwischensprachlich) e uma mentalidade transcultural (ibid), a competência simbólica.

Antes de abordar a definição da competência simbólica em si, vale a pena ressaltar que a noção de simbólico, para Kramsch, está vinculada a três dimensões: representação simbólica (symbolic representation), ação simbólica (symbolic action) e poder simbólico (symbolic power) (KRAMSCH, 2011a, p. 357). A representação simbólica está relacionada não só às funções conotativa e denotativa da linguagem, mas também à maneira como pensamos e organizamos os sentidos, símbolos e metáforas conceituais que se referem tanto ao mundo externo quanto moldam nossa mente. A ação simbólica, por sua vez, está associada à performatividade da língua e dos signos, à construção social da 
realidade através dos atos de fala performativos e ao impacto emocional e ideológico das palavras. O poder simbólico, por fim, abrange as relações intertextuais dos enunciados bem como sua discursividade e refere-se à ordem simbólica, ao posicionamento social bem como à historicidade dos discursos. Ele sublinha o poder das relações sociais e das desigualdades manifestadas na e pela linguagem. Essas três dimensões se manifestam nos chamados sistemas simbólicos - entre eles, a língua - e tangenciam o desenvolvimento da CS.

Kramsch define a CS como um agrupamento complexo que envolve as seguintes habilidades:

consciência dos valores simbólicos das palavras, habilidade de encontrara posição do sujeito mais apropriada, habilidade de compreender o amplo significado social e histórico dos eventos e entender as memórias culturais evocadas por sistemas simbólicos, habilidade de performar e criar realidades alternativas, ressignificando as questões (KRAMSCH, 2009b, p. 113).

Para que os estudantes possam desenvolver essa competência, eles precisam ocupar-seda potencialidade de produção de sentido da língua. Nesse sentido, Kramsch entende que a literatura, por conta do seu poder de imaginação e criação possui um potencial singular e pode alimentar a CS (KRAMSCH, 2006, p. 251). Dessa forma, a autora descreve os principais componentes desta competência, que correspondem, na sua visão,em certa medida ao potencial da literatura: produção de complexidade (production of complexity), tolerância à ambiguidade (tolerance of ambiguity) e forma enquanto sentido (form as meaning).

Produção de complexidade diz respeito ao entendimento da comunicação humana com uma ação mais complexa do que apenas falar a palavra certa para a pessoa certa da maneira correta (KRAMSCH, 2006, p. 251). É preciso entender antes que em muitas situações não há soluções nem boas, nem ruins, há as circunstâncias e diferentes possibilidades de lidar com elas. Nesse sentido a literatura pode apresentar situações e cenários de perspectivas parecidas (às vezes iguais ou muito distintas) com a vida real. Por tolerância à ambiguidade deve-se entender a sensibilidade para as contradições. Ocupar-se da literatura, de acordo com Kramsch, pode realçar os contrastes entre mitos e realidades, ações e palavras e em vez de colocar o foco na resolução dessas contradições, os estudantes podem prestar atenção em como conflitos são inerentes à língua e como esta 
pode ser usada para lidar com eles. Forma enquanto sentido refere-se à relevância da interação entre forma e significado, pois a produção de sentido está relacionada com sua percepção enquanto forma nos enunciados e os alunos de língua estrangeira tendem a ser mais atentos ao som, ritmo, formato, etc.

Assim, de acordo com o que foi descrito acima, a CS procura explorar toda a potencialidade da língua em suas diferentes dimensões e aspectos. A partir do exposto também entendemos que a CS pode ser aproximada do que García compreende por Translinguagem: "práticas discursivas múltiplas na quais sujeitos bilíngues se engajam para dar sentido aos seus mundos bilíngues" (GARCÍA, 2009, p. 45 apud GARCÍA; WEI, 2014, p. 22, ênfase no original). Embora reconheçamos que os termos com os quais, de um lado, García e Wei, de outro, Kramsch trabalham não se integrem totalmente, o que consideramos relevante para refletir sobre o desenvolvimento da CS como um caminho para uma prática translíngue são seus pressupostos (abordagem ecológica e perspectiva multi/plurilíngue), a compreensão da comunicação humana como uma atividade complexa, dinâmica e heterogênea circunscrita em diferentes escalas de tempo, a relação que ela estabelece entre linguagem e pensamento e, especialmente, o entendimento de que, a partir dela, uma consciência linguística, histórica, social e política, isto é, transdisciplinar, pode ser desenvolvida.Deste modo, ao abordar a CS nos cursos de graduação de Letras-Alemão pretende-se que os futuros professores de ALE devam compreender as relações ecológicas subjacentes à linguagem para que eles sejam capazes de desenvolver uma prática pedagógica que não seja orientada pela efetividade, senão pela sensibilidade para com os sujeitos plurilíngues e seu entorno.

\section{POESIA AFRO-ALEMÃ: NOTAS}

O objetivo desta seção é mostrar, de maneira breve, aspectos e nomes relevantes do surgimento da literatura afro-alemã, sobretudo em relação à poesia, a articular sua utilização com a perspectiva translíngue e o desenvolvimento da CS.

$\mathrm{O}$ termo afro-alemão (afro-deutsch) surgiu pela primeira vez na publicação Farbe bekennen: afro-deutsche Frauen auf den Spuren ihrer Geschichte (Assumir a cor: mulheres afro-alemãs em busca de sua história) (OGUNTOYE; OPITZ; SCHULTZ, 2006). As organizadoras compuseram o livro a partir de um estudo histórico de May Ayim 
sobre a presença de pessoas africanas na Alemanha, de narrativas autobiográficas de mulheres alemãs Negras bem como de poemas para “(...) revelar contextos sociais do racismo" (p. 9). Uma figura central para o surgimento do livro foi a afroestadounidense, poeta, lésbica e ativista Audre Lorde. Lorde foi professora convidada na Universidade Livre de Berlim na década de 1980 e a partir do conceito afroamerican, mulheres Negras alemãs juntamente com Lorde cunharam o termo afro-alemão:

\begin{abstract}
Afro-alemão nos parece plausível, uma vez que muitas de nós temos uma mãe alemã e um pai africano. No entanto, não queremos com isso enfatizar que temos uma parte materna ou paterna branca e a outra Negra. O que temos em comum é principalmente que somos Negras e uma parte significativa da nossa socialização e experiência de vida se desenvolveu no trato com a sociedade alemã. Uma sociedade que não consiste exclusivamente em alemães brancos [...].

Com o conceito afro-alemão compreendemos todos que desejam essa designação para si, indiferentemente se o pai ou a mãe ou os dois são Negros. Da mesma forma, [...] não se trata de uma marginalização segundo a origem ou cor da pele, nós sabemos muito bem o que significa sofrer exclusão. Pelo contrário, queremos opor 'afro-alemão' aos habituais termos improvisados, como 'mestiça', 'mulata' ou "de cor", como uma tentativa de nós mesmas nos definirmos ao invés de sermos definidas (OGUNTOYE; OPITZ; SCHULTZ, 2006, p. 10).
\end{abstract}

Aqui elas deixam evidente que esta auto-definição surge da necessidade de tornar conhecida entre elas e ao mundo suas existências e experiências por suas próprias palavras. As organizadoras também contam que pouco posteriormente à criação do livro foram fundadas as entidades políticas Iniciativa Negros na Alemanha (Initiative Schwarze Menschen in Deutschland - ISD) e a Mulheres Negras na Alemanha (ADEFRA Schwarze Frauen in Deutschland) que constituem parte do movimento Negro alemão.

Ainda em relação a isso, Audre Lorde desempenhou um papel fundamental, uma vez que ela defendia que os movimentos Negros estavam estabelecidos em uma rede diaspórica, na qual as fronteiras nacionais não deveriam ter nenhuma relevância;ela promovia um internacionalismo Negro (PIESCHE, 2012, p. 7). Piesche afirma que Lorde era consciente do poder da língua e sua força política e isso foi incorporado no movimento Negro alemão:

Para Lorde a língua era o meio de resistência, o falar tinha que enfrentar o calar da maioria da sociedade. No seu ensaio pioneiro "A transformação do silêncio em linguagem", Lorde descreveu a necessidade do enunciar a despeito dos riscos que o falar traz consigo. 
Lorde estava ciente do poder que a auto-definição e a enunciação de si simbolizam. Ela sabia quais provocações auto-definições aparentemente simples representam para o discurso social normativo. As assimilações que estavam por trás das auto-definições como Negra, poeta lésbica, teórica, mãe e ativista estavam ancoradas profundamente em uma historicidade, da qual vozes marginalizadas frequentemente eram excluídas. Isto foi também um ponto central de referência e de partida para o movimento de mulheres Negras e lésbicas na Alemanha (PIESCHE, 2012, p. 9 - grifos da autora).

Língua como meio de resistência. Quebrar o silêncio ao qual corpos marginalizados foram submetidos e, a partir disso, construir novas perspectivas. Este foi o ensejo por trás da auto-definição das mulheres afro-alemãs com base na experiência e solidariedade política de Audre Lorde. O aparecimento do termo afro-alemão estabeleceu também um processo complexo de atribuição de sentido e reposicionamento de subjetividades (KAMTA, 2012, p. 156). Mesmo Lorde conta como suas estudantes Negras alemãs tiveram primeiro uma percepção negativa do termo, uma vez que todas as denominações que elas conheciam, como "mulata", "mestiça", entre outras, eram depreciativas. Kamta (2012, p. 153) descreve que "a literatura afro-alemã surge como uma reação ao discurso binário do mestiço, que diferenciava rigidamente Negros e brancos e construía identidades raciais mestiças como estigmas raciais e como símbolo de degeneração de 'raça' e cultura". Essas mulheres entenderam que foram marginalizadas pela ideologia dominante e compreenderam também que elas poderiam recusar essa posição a elas atribuídas e criar uma própria e nova dentro das possibilidades de articulação da sociedade (2012, p. 155).

Neste contexto, a dimensão pessoal adquiriu uma importância significativa: dado que essas mulheres eram pouco ou nada visíveis na literatura produzida da época, elas começaram então a escrever desde suas próprias experiências. Dessa forma, a partir do encontro com Lorde, as mulheres afro-alemãs deram início a uma nova política de representação, que encontrou na língua um espaço de construção e especialmente um espaço de ação, uma vez que elas construíram não só uma nova definição de si mesmas e um fazer artístico - a criação do termo afro-alemã e a escrita literária - mas também novas práticas - a construção de um movimento político de solidariedade internacionalista não apenas com afro-descendentes, mas também com outros grupos minoritários.

Stefanie Kron (2009) apresenta os aspectos relevantes da produção literária afro- 
alemã e explica que

no geral, na criação literária de autoras Negras predominam ensaios político-filosóficos, principalmente textos autobiográficos e poesia, mas também formas textuais híbridas que não se permitem classificar nem pelada divisão de literatura ficcional e não-ficcional, nem por gêneros literários clássicos (KRON, 2009, s/p).

Como exemplo fundamental Kron destaca Farbe bekennen. Ela mostra que no livro se apresentam principalmente como temas e motivos o processo de construção de corpos brancos e Negros, a construção do significado a cor da pele, a (in)visibilidade e reflexão sobre a língua alemã e o racismo que ela é capaz de expressar. Especialmente a interação entre alemães brancos e Negros é focalizada, na qual brancos constituem a maior parte da sociedade e por conta disso representam a norma social, enquanto Negros são imaginados como "os outros". O olhar branco em relação aos Negros os posiciona, segundo Kron (2009), como sujeitos/objetos, que são percebidos através de estereótipos ou de maneira infantilizada e/ou sexualizada e são destituídos de história.

A autora menciona que muitos poemas da primeira geração de autores afroalemães - que nasceram da década de 1950 e 1960 - abordam a experiência traumática de serem sempre reconhecidos como "outros. Da mesma forma, o passado colonial da Alemanha também é tematizado dentro da literatura afro-alemã, pois ou ele é ocultado dos discursos históricos oficiais ou é interpretado como menos importante por conta de sua curta duração. Farbe bekennen trouxe à tona o colonialismo alemão e suas marcas.

As autoras afro-alemãs se ocupam das imagens coloniais para confrontá-las e então construir ou resgatar imagens, histórias e figuras positivas. Segundo Kron (2009), sua literatura busca lugares onde suas subjetividades Negras femininas possam ser articuladas. A fim de criar essa autoimagem positiva, as autoras recorrem a expressões linguísticas que não correspondem aos estereótipos coloniais. Da mesma maneira, elas buscam referências históricas que se relacionam com as identidades diaspóricas. Kron (2009) mostra que isso pode se apresentar, dentre outras formas, com o emprego de palavras que indicam movimentos, ou também com a evocação de figuras históricas como Soujourner Truth e Martin Luther King. Todos esses aspectos podem ser encontrados, por exemplo, na poesia de uma das expoentes vozes da literatura afro-alemã: May Ayim.

Nascida em Hamburgo, filha de pai ganês e mãe alemã, May Ayim foi pedagoga, poeta e ativista afro-alemã. Mudou-se mais tarde para Berlin, onde viveu até seu suicídio, 
em 1996. Seu trabalho de conclusão de licenciatura foi o primeiro trabalho acadêmico na Alemanha a abordar questões relativas às pessoas Negras no território alemão, estudo este incorporado ao livro Farbe bekennen, oferecendo um panorama histórico da presença Negra na Alemanha. Foi também em Farbe bekennen que Ayim publicou seus primeiros poemas. Além deste, publicou ensaios e poesias, dentre os quais se destacam Entfernte Verbindung: Rassismus, Antisemitismus, Klassenunterdrückung (Conexões Distantes: Racismo, Antissemitismo e Opressão de Classe) (1993) e blues in schwarz weiss (blues em preto e branco) (1995), e conta também com algumas publicações póstumas. No Brasil, seus poemas e ensaios têm sido vertido para o português brasileiro pela tradutora afro-brasileira Jessica Oliveira de Jesus. Neste artigo, analisaremos um dos poemas de May Ayim publicado no livro blues in schwarz weiss e reproduziremos também a respectiva tradução de Oliveira de Jesus.

Gostaríamos de destacar que o que foi considerado aqui não é, de fato, suficiente para abranger a diversidade da produção literária de autores afro-alemães/Negros na Alemanha. $\mathrm{O}$ objetivo foi antes mencionar aspectos e figuras relevantes que formaram o ponto de partida para novas perspectivas Negras não só dentro da sociedade alemã, mas também dentro da literatura de língua alemã. Esta perspectiva se vale especialmente da força poético-política da língua e, como já dito, inaugura um processo de reordenamento e/ou transformação não só subjetiva, mas também social, que rompe com visões monolíticas de sujeitos e suas identidades étnico-raciais em especial, e se entende como uma forma de enfrentamento aos discursos homogeneizantes, opressores e excludentes, pois não só os questiona, como também propõe alternativas. Nesse sentido, ocupar-se da poesia afro-alemã também oferece uma possibilidade de alinhamento à perspectiva translíngue, pois, como apontam García e Wei (2014, p. 43): “Translinguagem, para nós, refere-se a ações de languaging que promovem um processo político de transformação social e subjetiva que resiste às assimetrias de poder que a língua e outros códigos de produção de significados, associados com uma ou outra ideologia nacionalista, produzem". Além disso, por se tratar de literatura, a poesia afro-alemã e os temas que dela surgirem podem proporcionar uma discussão que aborde não só questões linguísticas, mas também questões históricas, sociais e políticas e, assim, possibilitar o desenvolvimento da CS. 


\section{COMPETÊNCIA SIMBÓLICA ATRAVÉS DA POESIA AFRO-ALEMÃ}

Nesta seção analisaremos como exemplo um poema da autora afro-alemã May Ayim e posteriormente discutiremos seu potencial de contribuir com o desenvolvimento da CS nas aulas de ALE no contexto de formação inicial de professores. O texto integra o livro blues in schwarz weiss (1995, p.53-54) de Ayim e foi dedicado ao ativista Martin Luther King. O poema na íntegra bem como sua versão em português, traduzida por Jessica Oliveira de Jesus (2018, p. 146-468), encontram-se em anexo.

No poema die zeitdanach/o tempo por vir, Martin Luther King apresenta-se como interlocutor do eu-lírico, um eu lírico feminino, que o chama de Bruder/Irmão e sobretudo a bandeira que o ativista defendia é também defendida neste poema. $\mathrm{O}$ famoso discurso de Luther King, I Have a Dream, em que ele diz ter um sonho, ressoa em todo o poema e este sonho parece inspirar o sonho do eu-lírico: o desejo de que as pessoas não nasçam mais gritando, senão rindo em cores de arco-íris. É um sonho que deseja uma mudança de perspectiva desde o início, desde o nascimento. Este é carregado pelo eu-lírico atrás de seu punho cerrado e erguido, símbolo de luta, contra a morte e pelo futuro. No futuro também há a visão, onde o eu-lírico está no chão, deitado, com um olhar sereno, porém com um buraco na cabeça. Esta imagem evoca o assassinato de King, alvejado com um tiro na sacada de um hotel, onde estava hospedado na cidade de Memphis (Tennessee) para apoiar uma greve de lixeiros Negros. A morte também ocupa espaço neste poema, embora o último verso arremate a ideia central do texto, a saber, a continuação da luta antirracista. Se King tinha um sonho e não o conseguiu realizar em vida, o eu-lírico, alimentado por este sonho, também estabelece um próprio e está decidido a mudar a realidade, acompanhado, mas se necessário, sozinho; além disso tem a certeza que ainda depois de sua morte a luta continuará.

Um dos aspectos mais proeminentes no texto é a temporalidade, que salta do futuro para o passado para o presente, que é indicada não só por tempos verbais (daß es eines tages anders sein wird / [...] das hast du geträumt [...] / que um dia tudo seja diferente [...] isso você sonhou [...]; ich trage meinen traum / eu carrego meu sonho), mas também por advérbios (die bald nicht mehr stehen / que logo não estarão mais de pé), e ainda por substantivos, como, por exemplo, traum/sonho, vision/visão, que exprimem uma noção de futuro e também bewältigt/superado e vergangenheit/passado, que fazem 
referência a algo que já passou. A historicidade é evocada pela figura de King - que não é só uma personalidade e interlocutor do poema, ele também simboliza um contexto social específico - a luta por direitos civis para a população Negra nos EUA nos anos 1950 e 1960; do mesmo modo, o último verso faz referência à luta do povo moçambicano por sua independência, que ocorreu em 1975. A frase a luta continua foi usada como grito de guerra pela Frente de Libertação de Moçambique (FRELIMO), partido político que esteve à frente do processo de independência. Essas duas referências são, por sua vez, movimentos distintos, mas que compartilham aspectos e um horizonte em comum: identidades Negras,um desejo de liberdade e a luta por ela.

Uma outra particularidade do poema refere-se ao uso das cores: na primeira estrofe temos schwarz/preto, blutrot/vermelho-sangue, grün/verde e wahre farben/cores verdadeiras; na segunda estrofe aparecem as regenbogenfarben/cores do arco-íris; na quinta estrofe, weiß/branco; na estrofe seguinte há as pfefferfarben/cores de pimenta. Com todas as cores são feitas associações. Algumas são comparações, por exemplo, preto como a meia-noite, verde como as árvores, ou branco como sal de lágrima. Vermelho-sangue contém a associação na própria construção da palavra - um vermelho que simboliza o sangue. Para o eu-lírico, há as cores verdadeiras, e estas talvez só possam ser pintadas pelas crianças no útero - isto é, antes do contato com mundo, e talvez por isso essas cores não possam ser comparáveis. As outras duas referências a cores, no plural, representam na verdade paletas, a paleta de cores do arco-íris (colorido, alegre) e a de cores de pimenta (cores quentes, ardentes): a primeira paleta faz parte do sonho do eu-lírico e é relacionada a uma expressão humana, rir em cores de arco-íris; a segunda está associada ao símbolo de luta política, punho erguido em cores de pimenta. É preciso ter alegria para rir, mas também vigor para lutar.

A noção de luta, de confronto é evidente no texto. Aqui o punho erguido é novamente destacado, pois demonstra uma noção de enfrentamento, de posicionar-se. Além disso as palavras demonstrationen/manifestações e protestmärsche/marchas de protesto também dão a dimensão de uma luta coletiva - embora, no contexto em que essas palavras são mencionadas, o eu-lírico esteja falando que eles se utilizam de manifestações e protestos para defender sua democracia, uma democracia ainda estruturada pelo racismo. Por fim, a própria palavra luta aparece no último verso,sublinhando de maneira contundente o enfrentamento antirracista que o poema expressa. 
O poema, além disso, faz uma crítica a cooptação do sonho de Martin Luther King para transformá-lo em mercadoria: fizeram dele passado, o esvaziaram de sentido - uma vez que eles o consideram "superado", isto é, ele teria se tornado obsoleto - e o venderam. O eu-lírico então resgata esse sonho, dizendo que ele não só continua atual, como também inspira outros, inclusive o seu próprio, e tal qual King e os moçambicanos da FRELIMO se mobilizaram em um movimento antirracista (e anti-colonialista) assim também o eulírico ergue seu punho, carregando seu sonho antirracista.

Ainda é interessante destacar o uso do vocativo Bruder/Irmão. Com exceção do último verso, o vocativo é a única palavra no poema escrita com a inicial maiúscula - aqui é importante ressaltar que, de acordo com a norma ortográfica alemã, todos os substantivos são escritos com a inicial maiúscula. May Ayim transgride essa norma, escreve seus poemas inteiros em caixa baixa e, por isso, a inicial maiúscula assume uma conotação especial. Além de demonstrar de certa forma respeito pela figura de Martin Luther King, a palavra sugere também a conexão dos povos da diáspora. Conforme Oliveira de Jesus (2018) argumenta em sua tradução de alguns dos poemas de Ayim, Negros e Negras constituem uma comunidade transnacional, afro-diaspórica, e este poema expressa a dimensão desta comunidade. Os versos I Have a Dream e AMEN - A LUTA CONTINUA complementam esse sentido, na medida em que simbolizam comunidades negras em lugares distintos no mundo, mas que, no poema, somam-se à comunidade negra alemã. $\mathrm{O}$ fato de estes versos estarem escritos em outros idiomas também evidencia a composição da comunidade afro-diaspórica a despeito da língua que cada integrante ou grupo de integrantes utiliza.

Um outro aspecto relevante deste poema que pode ser explorado é o fato de ele ser endereçado a uma figura já morta (como expressa a epígrafe do texto). O efeito desta homenagem póstuma, a tarefa de conservar a memória de King e seu sonho, sem vendelos,mensuram a complexidade da performatividade do poema, a palavra-ação que de fato resgata a memória de King e de seu discurso mais célebre, alguém que Ayim mesma não conheceu e nem foi conhecida por ele, mas que seu eu-lírico chama de irmão e o tem como inspiração.

A partir destas considerações, buscamos, a seguir, refletir qual o potencial deste texto - como exemplo de poesia afro-alemã - de contribuir para o desenvolvimento da CS, como possibilidade de uma prática translíngue no contexto de aulas de ALE nos cursos de 
licenciatura em Letras-Alemão.

O poema oferece subsídios para explorar os componentes da CS, a saber, forma enquanto sentido, tolerância à ambiguidade e produção de complexidade. Em relação ao primeiro componente, pode-se considerar, por exemplo,que é, também, pelas formas "erhobenerfaust/punho erguido", demonstrationen/manifestações, protestmärsche/ marchas de protesto e luta que o sentido da luta antirracista é construído no poema. De outro modo, os alunos podem ser sensibilizados para tolerância à ambiguidade a partir da reflexão sobre a ambivalência das palavras: embora o texto represente a força da conexão da rede afro-diaspórica e, portanto, evoque a noção de uma resistência antirracista coletiva, o eu-lírico afirma que, se preciso, lutará sozinho; as manifestações e protestos, símbolos de reivindicação de direitos, são mencionados no texto como ações que conservam uma democracia desigual - e, logo, uma não-democracia; isso demonstra que a ambivalência é inerente a língua. Além disso, o fato de a própria palavra de certa maneira falhar (reden hilft kaum noch, Bruder/conversar já não ajuda, Irmão) e a sugestão de que meinungsfreiheit/liberdade de opinião poderia significar, na verdade, expressar-se sem ter consciência do peso das palavras nem das suas dimensões simbólicas podem ser abordados como aspectos que indicam a complexidade do que é falar, e a partir disso atentar-se para a produção de complexidade.

Mais do que isso, o que avaliamos como relevante neste poema é a abertura que ele oferece para a discussão de temas que se dão a partir da língua, proporcionam, no entanto, debates que vão para além dela. É pela língua que a figura de King é evocada, mas ela simboliza, como já mencionado, um contexto e uma demanda social localizados em um tempo e espaço definidos, que se conectam com outros contextos e reivindicações similares circunscritos em outros tempos e espaços, como a luta pela independência de Moçambique, a demanda das mulheres afro-alemãs e, inclusive, movimentos antirracistas atuais. Neste sentido, a compreensão do poema passa também pela discussão das dimensões históricas, sociais e políticas que se entrelaçam no texto. Nele, as fronteiras sejam elas geográficas, sejam elas linguísticas - entre esses contextos não estão postas, elas são mobilizadas não a partir dos seus limites simbólicos, senão pela forma como se integram. Este enfoque traz pro centro do debate a necessidade de desenvolver uma percepção dos usos da(s) língua(s) a partir de uma perspectiva transdisciplinar. É nesse sentido que a poesia afro-alemã pode contribuir para o desenvolvimento da CS e para a 
construção de uma abordagem translíngue no ensino de ALE, já que ela potencializa a força da linguagem também como forma de resistência.

Consideramos ainda que se ocupar da poesia afro-alemã, do seu surgimento enquanto movimento literário que buscou jogar luz sobre aspectos até então não abordados e refletir sobre a criação do termo afro-alemão contribui para quebrar estereótipos ainda muito presentes sobre identidades socioculturais homogêneas e relações étnico-raciais, como por exemplo, em relação à lógica colonial que coloca Negros e alemães como duas categorias distintas que se anulam: ou se é Negro ou se é alemão. Logo, um sujeito posicionar-se como afro-alemão quebra essa dicotomia (cf. KILOMBA, 2006) e se apresenta como uma forma de enfrentamento a esta visão. Assim, abordar essas questões com vistas a desenvolver a CS desde uma perspectiva translíngue significa fazer essas discussões incluindo as perspectivas dos alunos, criando um espaço em que todas as suas línguas e práticas discursivas possam ser acolhidas, de modo a criar novas práticas discursivas mais conscientes e críticas, que questionem os limites simbólicos.

\section{CONSIDERAÇÕES FINAIS}

Neste texto buscamos articular a noção de CS desde uma perspectiva translíngue e discutir seu desenvolvimento na formação de professores de alemão a partir da utilização da poesia afro-alemã. Desta forma, mobilizamos em primeiro lugar a concepção da CS e a aproximamos do enfoque translíngue, bem como apresentamos um breve panorama do surgimento e ainda alguns aspectos gerais da produção literária afro-alemã. Em seguida analisamos como exemplo o poema "die zeitdanach", de May Ayim, seguido da respectiva tradução em português, “o tempo por vir”, de Jéssica Oliveira de Jesus, e a partir da análise tentou-se demonstrar como o poema oferece subsídios para se trabalhar a CS nas aulas de ALE, e também a importância de o texto abordar um tema sociopolítico que julgamos relevante para os estudantes. Queremos, contudo, enfatizar que a poesia afroalemã não deve ser resumida somente a esse tema. Antes, queremos destacar a importância de ocupar-se também de textos literários que apresentem uma perspectiva política.

Ademais, julgamos a temática do poema analisado de fundamental importância para o contexto de formação de professores de alemão. Como parte da educação, 


\section{REVISTA $\mathbf{X}$}

consideramos que o ensino de língua estrangeira, sobretudo nas Instituições de Ensino Superior, deve ter um compromisso com a emancipação e justiça social, porque também entendemos que não há ensino neutro: se não se reflete e não se questiona as injustiças e desigualdades sociais historicamente herdadas, contribui-se para mantê-las. Neste sentido, a utilização do poema "die zeitdanach", por exemplo, em sala de aula pode iniciar uma discussão sobre racismo, que deve ser complementada a partir de outros textos e discussões e estar voltada, na formação inicial de professores, para o debate sobre como construir práticas de ensino antirracistas.

Consideramos, por fim,que as reflexões aqui feitas são introdutórias para pensar uma prática translíngue no ensino de ALE em contexto universitário, no entanto, julgamos que desenvolver a CS através da poesia afro-alemã se mostra como um caminho possível para este propósito. Desta forma, outras pesquisas que possam contribuir para um ensino de ALE sob esse enfoque se fazem necessárias.

\section{REFERÊNCIAS}

ARANTES, P. Formação docente em língua alemã: avanços e desafios de institucionalização de sentidos em documentos oficiais da licenciatura. In: UPHOFF, D. et al. Alemão em contexto universitário. Ensino, pesquisa e extensão. São Paulo: FFLCH/USP, p.11-34, 2019.

AYIM, M. Blues in Schwarz Weiss: Gedichte. 2. Ed. Berlin: Orlanda Frauenverlag, 1996.

GARCÍA, O; WEI, L. Translanguaging: Language, Bilingualism and Education. Nova York: Palgrave Macmillan, 2014.

KAMTA, F. S. Ideologie und Identifikation in der afrodeutschen Literatur. In: HOFMANN, M.; MORRIEN, R. (Org.). Deutsch-afrikanische Diskurse in Geschichte und Gegenwart: Literatur- und kulturwissenschaftlichen Perspektiven. Amsterdam: Rodopi, p. 151-169, 2012.

KILOMBA, G. Wo kommst $d u$ her? 2006. Disponível em: $<$ https://heimatkunde.boell.de/2006/05/01/wo-kommst-du-her > Acesso em: 27 mar. 2020.

KRAMSCH, C. From communicative competence to symbolic competence. The Modern Language Journal. New Jersey, v. 90, n. 2, p. 249-251, 2006.

KRAMSCH, C. The Multilingual Subject: What foreign language learners say about their experience and why it matters. Oxford: Oxford University Press, 2009a. 
KRAMSCH, C. Discourse, the symbolic dimension of Intercultural Competence. In: HU, A; BYRAM, M. (Org.) Interkulturelle Kompetenz und fremdsprachliches Lernen. Modelle, Empirie, Evaluation / Intercultural competence and foreign language learning: models, empiricism, assessment. Tübingen: Narr, p.107-121, $2009 \mathrm{~b}$.

KRAMSCH, C. The symbolic dimensions of the intercultural. Language Teaching, Cambridge, v. 44, n. 3, p. 354-367, 2011 a.

KRAMSCH, C. Symbolische Kompetenz durch literarische Texte. Fremdsprache Deutsch, Berlin, v. 44, p. 35-40, 2011 b.

KRAMSCH, C. Teaching Foreign Languages in an Era of Globalization: Introduction. The Modern Language Journal, v. 98, n. 1, p. 296-311, 2014.

KRAMSCH, C.; WHITESIDE, A. Language Ecology in Multilingual Settings. Towards a theory of symbolic Competence. Applied Linguistics, Oxford, v. 29, n. 4, p. 645-671, 2008.

KRON, S. Afrikanische Diaspora und Literatur Schwarzer Frauen in Deutschland, 2009. Disponível em: <https://heimatkunde.boell.de/2009/02/18/afrikanische-diaspora-undliteratur-schwarzer-frauen-deutschland>. Acesso em 20 nov. 2019.

OGUNTOYE, K.; OPITZ, M.; SCHULTZ, D. (Org.). Farbe Bekennen: Afro-deutsche Frauen auf den Spuren ihrer Geschichte. 3. Ed. Berlin: Orlanda Frauenverlag, 2006.

OLIVEIRA DE JESUS, J. May Ayim e a tradução de poesia afro-diaspórica de língua alemã. 165 f. Dissertação (Mestrado em Estudos da Tradução), Centro de Comunicação e Expressão, Universidade Federal de Santa Catarina, Florianópolis, 2018.

PIESCHE, P. (Org.). Euer Schweigen schützt euch nicht: Audre Lorde und die schwarze Frauenbewegung in Deutschland. Berlin: Orlanda Frauenverlag, 2012.

WEI, L. Translanguaging as a Practical Theory of Language. Applied Linguistics, Oxford, v. 39, n. 1, p. 9-30, 2017. 
de uma ainda viva para um já morto poema em memória de Martin Luther King

\section{o tempo por vir}

que um dia tudo seja diferente melhor

isso você sonhou, Irmão

preto como a meia-noite vermelho-sangue e verde como as árvores

que logo não estarão mais de pé

- as cores verdadeiras

talvez só as crianças pintem

no útero

talvez -

eu também tenho um sonho, Irmão

que um dia as pessoas

não venham ao mundo gritando

mas rindo

só rindo

nas cores do arco-íris

eu carrego meu sonho

atrás

do punho erguido

contra a morte e pelo tempo por vir

pois

conversar já não ajuda, Irmão

eles chamam isso de liberdade de opinião

e também de manifestação e marchas de protesto

eles precisam delas

para sua democracia

e continuam e continuam

e continuam

eles conservaram seu sonho

conservaram e venderam, Irmão

cartões postais e pôsteres

de três linhas em um livro de história

$\gg$ I Have a Dream«

um romance concluído

e dele

fizeram passado

branco como sal de lágrima

e lá onde vivo

eles chamariam de »superado«, irmão

eu carrego meu sonho

atrás

do punho erguido

em cores de pimenta

e começo aos poucos 
fange endlich an

mit meiner schwester

und meiner freundin an der hand mit

meinen brüdern und

wenn es sein soll

auch allein

- damit es endlich anders werden muß!

ich habe einen traum

da kommen menschen nicht mehr schreiend

zur welt

und eine vision

da lieg ich mit friedlichen augen

und einem loch im kopf

AMEN - A LUTA CONTINUA começo finalmente

com minha irmã

e de mãos dadas com minha namorada

com meus irmãos e

se preciso for

também sozinha

- para que enfim seja

diferente!

eu tenho um sonho

que as pessoas não venham ao mundo

gritando

e uma visão

lá estou com olhos serenos no chão

e um buraco na cabeça

AMEN - A LUTA CONTINUA

Für Linton

Und John
E John

Recebido em: 15 dez. 2019.

Aceito em: 15 mar. 2020. 